\title{
organic papers
}

Acta Crystallographica Section E

Structure Reports

Online

ISSN 1600-5368

Masood Parvez, * Ian R. Hunt and Brian A. Keay

Department of Chemistry, The University of Calgary, 2500 University Drive NW, Calgary, Alberta, Canada T2N $1 \mathrm{~N} 4$

Correspondence e-mail: parvez@ucalgary.ca

\section{Key indicators}

Single-crystal X-ray study

$T=200 \mathrm{~K}$

Mean $\sigma(\mathrm{C}-\mathrm{C})=0.006 \AA$

$R$ factor $=0.050$

$w R$ factor $=0.221$

Data-to-parameter ratio $=13.9$

For details of how these key indicators were automatically derived from the article, see http://journals.iucr.org/e

\section{2-Phenylcyclohexyl 3-furancarboxylate}

The crystal structure of the title compound, $\mathrm{C}_{17} \mathrm{H}_{18} \mathrm{O}_{3}$, contains molecules that are separated by normal van der Waals distances. The cyclohexyl ring adopts a classical chair conformation, while the furan and phenyl rings are individually planar. The molecular dimensions are as expected.

\section{Comment}

The intramolecular Diels-Alder reaction with a furandiene (IMDAF reaction) is a useful reaction for the creation of three rings with up to five stereogenic centers in one reaction (Keay \& Hunt, 1999). To date, no-one has reported an asymmetric version of this reaction. trans-2-Arylcyclohexanol esters of 3furoic acid were prepared as potential chiral auxiliaries for studying the asymmetric IMDAF reaction. AM1 calculations indicated that the large aryl ring would preferentially block one face of the furandiene thereby leading to high diastereoselectivity in the IMDAF reaction. The structure of 2phenylcyclohexyl 3-furancarboxylate, (I), was determined to establish if, in the solid state, the large aryl ring would block one face of the furan ring.

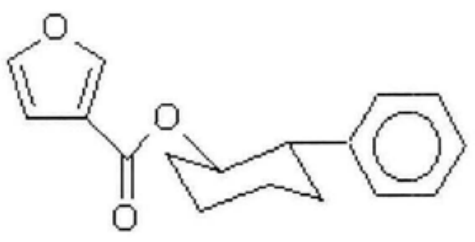

(I)

The molecular dimensions are normal and lie within expected values for corresponding bond distances and angles (Orpen et al., 1994). The C1-C6 cyclohexyl ring adopts a classical chair conformation, with puckering parameters (Cremer \& Pople, 1975) $Q=0.568$ (5) $\AA, \theta=177.3(5)^{\circ}$ and $\omega=$ $55(9)^{\circ}$. The phenyl ring is essentially planar with the maximum deviation of any atom from the mean plane being 0.007 (3) $\AA$. The five-membered furan ring is also planar. The structure is devoid of any undesirable interactions.

\section{Experimental}

To a mixture of 3-furoic acid $(111 \mathrm{mg}, 0.99 \mathrm{mmol})$ in dry methylene chloride $(2 \mathrm{ml})$ and dry DMF $(5 \mu \mathrm{l})$ at $273 \mathrm{~K}$ under a nitrogen atmosphere, oxalyl chloride ( $86 \mu \mathrm{l}, 1.1$ equivalents) was added. The solution was stirred at $273 \mathrm{~K}$ for $15 \mathrm{~min}$, then at room temperature for $3 \mathrm{~h}$. after which the solvent was removed in vacuo. After redissolving the residue in dry methylene chloride $(2 \mathrm{ml})$, a solution of trans-2phenylcyclohexanol $(164 \mathrm{mg}, 0.93 \mathrm{mmol})$ in dry methylene chloride
C 2001 International Union of Crystallography Printed in Great Britain - all rights reserved
Received 10 July 2001 Accepted 23 July 2001 Online 31 July 200 


\section{organic papers}

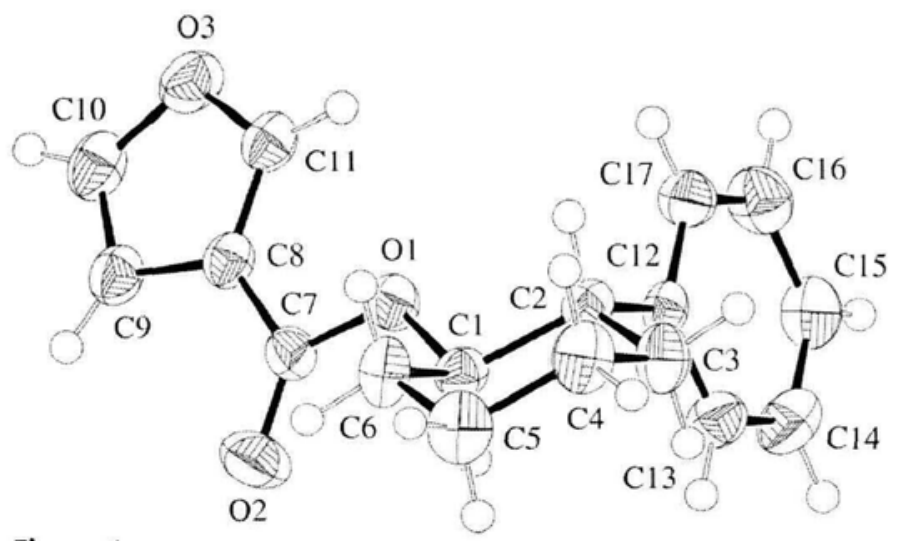

Figure 1

ORTEPII (Johnson, 1976) drawing of (I). Displacement ellipsoids have been plotted at the $50 \%$ probability level.

( $2 \mathrm{ml})$ was added followed by dry pyridine $(80 \mu \mathrm{l})$. The reaction mixture was stirred at room temperature overnight. After adding $\mathrm{CH}_{2} \mathrm{Cl}_{2}(20 \mathrm{ml})$, the solution was washed with $5 \% \mathrm{HCl}(25 \mathrm{ml}) . \mathrm{Et}_{2} \mathrm{O}$ $(20 \mathrm{ml})$ was added, then the organic phase was washed with water ( $25 \mathrm{ml})$, dried over $\mathrm{MgSO}_{4}$, then filtered and evaporated in vacuo to give the crude product as an oil. Purification via a short column (silica gel, EtOAc) followed by radial chromatography (EtOAc/hexanes, 7:1) gave the desired ester, (I).

\section{Crystal data}

$\mathrm{C}_{17} \mathrm{H}_{18} \mathrm{O}_{3}$

$M_{r}=270.31$

Monoclinic, $P 2_{1} / n$

$a=5.5332(11) \AA$

$b=12.841(2) \AA$

$c=20.088(3) \AA$

$\beta=96.52(2)^{\circ}$

$V=1418.1(4) \dot{\mathrm{A}}^{3}$

$Z=4$

Data collection

Rigaku AFC-6S diffractometer $\omega / 2 \theta$ scans

2796 measured reflection

2520 independent reflections

1156 reflections with $I>2 \sigma(I)$

$R_{\text {int }}=0.06$

$\theta_{\max }=25.0^{\circ}$

$h=0 \rightarrow 6$

$k=0 \rightarrow 15$

$l=-23 \rightarrow 23$

3 standard reflections

every 200 reflections

intensity decay: $<1.0 \%$

\section{Refinement}

Refinement on $F^{2}$

$R\left[F^{2}>2 \sigma\left(F^{2}\right)\right]=0.050$

$w R\left(F^{2}\right)=0.221$

$S=1.02$

2520 reflections

181 parameters

$\mathrm{H}$-atom parameters constrained

Most of the $\mathrm{H}$ atoms were located from difference maps. The $\mathrm{H}$ atoms were included at geometrically idealized positions with $\mathrm{C}-\mathrm{H}=$ $0.95-1.00 \AA$, in a riding mode with isotropic displacement parameters 1.2 times the displacement parameters of the atoms to which they were attached.

Data collection: MSC/AFC Diffractometer Control Software (Molecular Structure Corporation, 1988); cell refinement: $M S C / A F C$ Diffractometer Control Software; data reduction: TEXSAN (Molecular Structure Corporation, 1994); program(s) used to solve structure: SAPI91 (Fan, 1991); program(s) used to refine structure: SHELXL97 (Sheldrick, 1997); molecular graphics: TEXSAN; software used to prepare material for publication: SHELXL97 (Sheldrick, 1997).

The authors thank the Natural Sciences and Engineering Research Council, Canada, for providing the diffractometer through an equipment grant to the University of Calgary.

\section{References}

Cremer, D. \& Pople, J. A. (1975). J. Am. Chem. Soc. 97, 1354-1358. Fan, H.-F. (1991). SAPI91. Rigaku Corporation, Tokyo, Japan.

Johnson, C. K. (1976). ORTEPII. Report ORNL-5138. Oak Ridge National Laboratory, Tennessee, USA.

Keay, B. A. \& Hunt, I. R. (1999). Adv. Cycloaddit. 6, 173-210.

Molecular Structure Corporation (1988). MSC/AFC Diffractometer Control Software. MSC, 3200 Research Forest Drive, The Woodlands, TX 77381, USA.

Molecular Structure Corporation (1994). TEXSAN. MSC, 3200 Research Forest Drive, The Woodlands, TX 77381, USA

Orpen, A. G., Brammer, L., Allen, F. H., Kennard, O., Watson, D. G. \& Taylor, R. (1994). Structure Correlation, Vol. 2, edited by H.-B. Bürgi \& J. D. Dunitz, pp. 751-858. New York: $\mathrm{VCH}$

Sheldrick, G. M. (1997). SHELXL97. University of Göttingen, Germany. 